\title{
Celiac Disease, Gluten-Free Diet, and Metabolic and Liver Disorders
}

\author{
Marco Valvano ${ }^{+}\left(\mathbb{D}\right.$, Salvatore Longo ${ }^{+} \mathbb{D}$, Gianpiero Stefanelli, Giuseppe Frieri, Angelo Viscido \\ and Giovanni Latella *(D)
}

Gastroenterology, Hepatology and Nutrition division, Department of Life, Health and Environmental Sciences, University of L'Aquila, 67100 L'Aquila, Italy; valvano.marco@libero.it (M.V.); salvator.longo@gmail.com (S.L.); giastefanelli@gmail.com (G.S.); g.frieri@libero.it (G.F.); angelo.viscido@univaq.it (A.V.)

* Correspondence: giolatel@tin.it; Tel.: +39-0862-434735

t These authors contributed equally to this work.

Received: 6 March 2020; Accepted: 26 March 2020; Published: 28 March 2020

check for updates

\begin{abstract}
Celiac disease (CD) is a chronic autoimmune enteropathy triggered by the ingestion of gluten in genetically predisposed individuals. At the time of diagnosis, the frequency of nonalcoholic fatty liver disease (NAFLD) and nonalcoholic steatohepatitis in individuals with CD appears to be similar to that of the general population, although a lower body mass index and a lower rate of hypercholesterolemia and type 2 diabetes mellitus are observed at diagnosis in CD patients. The effect of a gluten-free diet (GFD) in individuals with these liver and metabolic disorders is still a matter of debate. The aim of this study was to investigate the links between a GFD and metabolic/liver disorders in CD patients. A systematic electronic search of the literature from January 2009 to December 2019 was performed using Medline, Web of Science, Scopus, and the Cochrane Library. Only papers written in English concerning metabolic and liver disorders in adult patients with CD were included. Out of 1195 citations, 14 eligible studies were identified. Increases in the frequency of NAFLD, weight gain, and alterations of the lipid profile suggest that important changes happen in celiac patients on a GFD, though the physiopathology of these conditions is unclear. Although a GFD is the only effective treatment available for $\mathrm{CD}$, liver function, body weight, and metabolic and nutritional profiles should be monitored in patients on a GFD.
\end{abstract}

Keywords: celiac disease; gluten-free diet; hepatic steatosis; nonalcoholic steatohepatitis; NASH; nonalcoholic fatty liver disease; NAFLD; dyslipidemia; hypercholesterolemia; hypertriglyceridemia; body weight; body mass index; BMI; type 2 diabetes mellitus; T2DM

\section{Introduction}

Celiac disease (CD) is a chronic autoimmune enteropathy triggered by the ingestion of gluten in genetically predisposed individuals: it induces damage to the mucosa of the small intestine, which is characterized by atrophy of the villi [1]. The clinical manifestations are heterogeneous and include both "classical CD" (symptoms of malabsorption, e.g., diarrhea, steatorrhea, and weight loss) and "nonclassical CD" (extraintestinal symptoms, e.g., anemia, osteoporosis, liver disorders, and depression) [1,2].

Historically, at the time of diagnosis, patents with CD had a reduced body mass index (BMI) compared to the general population [3]. In the last few decades, increasing numbers of CD patients with a normal or high BMI at the time of diagnosis was reported [4-9]. This could be due to the fact that early diagnosis has become more frequent in recent years (late diagnoses were more common in the past), allowing for a reduction in the rate of both intestinal mucosal atrophy and related 
malabsorption [9]. Furthermore, the milder forms of $C D$ (those which do not get worse by time) are increasingly recognized.

The mean BMI in CD patients at diagnosis is lower than in the general population (22.4-24.8 vs. 24.2-27.9, respectively) [10-12]. However, although the frequency of CD patients being overweight is lower than in the general population, overweight patients are increasingly being found at diagnosis. It has been observed that the nutritional status of patients who have received a diagnosis of $C D$ in the last few years is better than that of those diagnosed in previous years. In one study, out of 155 patients diagnosed with CD between 1994 and 2017, patients who were overweight at diagnosis were observed only after 2002, and obesity was observed only after 2010 [9].

The clinical presentation of CD has changed over time, with "nonclassical CD" (extraintestinal symptoms) being more common than classical symptoms of malabsorption [13]. Out of the atypical manifestations of $C D$, liver involvement is among the most common [14]. In a meta-analysis including eleven studies, pooled prevalences of positive celiac serology and biopsy-proven CD in cryptogenic hypertransaminasemia were $6 \%$ (95 CI 3\% to $10 \%)$ and $4 \%$ (95\% CI $1 \%$ to $7 \%$ ), respectively [15]. Pooled prevalence of hypertransaminasemia in newly diagnosed CD was $27 \%$ (95\% CI $13 \%$ to $44 \%$ ). Moreover, different prevalences of elevated levels of transaminases were reported. In a cross sectional study including 313 untreated and 339 treated adult patients with CD and 237 non-celiac controls, the proportion of patients with hypertransaminasemia in the untreated CD group (11\%) did not differ significantly from that in the treated CD $(8 \%)$ or non-celiac control group $(9 \%)(p<0.587)$ [16]. More recently, it has been reported that approximately $40 \%$ of patients had elevated liver function tests (LFTs) at CD diagnosis and that the majority were then nominalized after a gluten-free diet (GFD) [10]. LFTs were defined as abnormal liver enzyme levels based on the Third National Health and Nutrition Examination Survey III criteria (NHANES III). Gluten-sensitive hypertransaminasemia in celiac disease should be considered as an infrequent and often subclinical finding. The values of transaminases usually normalize within 6 to 12 months after the patient starts a gluten-free diet (GFD) [17].

On the other hand, the frequency of nonalcoholic fatty liver disease (NAFLD) and nonalcoholic steatohepatitis (NASH) in CD patients at the time of diagnosis appears to be similar to that of the general population $(5.4 \%$ vs. $4.5 \%, p=0.545)$ [10].

NAFLD is a common condition in the general population, and its prevalence is extremely heterogeneous all over the world. In Europe, its frequency ranges from $4 \%$ to $49.62 \%$ (overall prevalence of $23.71 \%$; confidence interval $16.12 \%-33.45 \%$ ). The prevalence of NASH is lower, ranging from $3 \%$ to $5 \%[18,19]$. Furthermore, NAFLD patients have a higher risk of a new diagnosis of CD compared to the general population [20,21], despite celiac patients having a lower risk for metabolic syndrome before the start of a GFD [20].

In fact, the prevalence of type 2 diabetes mellitus (T2DM) at diagnosis in celiac patients is lower or similar to that of the general population $(2.7 \%-3.1 \%$ vs. $3 \%-9.6 \%)$ [22,23]. In a UK study, CD patients showed a low rate of hypercholesterolemia compared to the general population ( $3.0 \%$ vs. $4.8 \%$; odds ratio-OR: 0.58) [24].

The effect of a GFD in individuals with these conditions is still a matter of debate. It has been hypothesized that gluten-free foods could play a key role in the etiology of metabolic and hepatic disorders. It has been demonstrated that the consumption of gluten-free products leads to higher lipid and carbohydrate intake [25-28]. However, it is not clear if gluten-free products contribute to weight gain, and furthermore, the role of a GFD in the development of NAFLD remains undetermined.

The aim of our study was to investigate the links between a GFD and metabolic/liver disorders in $\mathrm{CD}$ patients. In particular, we investigated the association between changes in body weight and the lipid profile and the frequency of T2DM and NAFLD before and after the start of a GFD. 


\section{Materials and Methods}

A systematic electronic search of the literature (written in English) from January 2009 to December 2019 was performed using Medline (PubMed), Web of Science, Scopus, and the Cochrane Library. The search included a combination of Medical Subject headings (MeSH) and keywords:

"celiac disease/coeliac disease", "steatosis", "hepatic steatosis", "steatohepatitis", "nonalcoholic steatohepatitis", "NASH", "nonalcoholic fatty liver disease", "NAFLD", "dyslipidemia", "hypercholesterolemia", "hypertriglyceridemia", "weight gain", "body mass index", "BMI", and "type 2 diabetes mellitus".

The search was limited to studies conducted on human, adult CD patients on a GFD. Studies on pediatric populations (0-16 years) were excluded. We considered prospective and retrospective cohort studies, case-control studies, and analytical cross-sectional studies.

\section{Results}

Figure 1 shows the results of the literature search, as assessed by the three authors (M.V., S.L., and G.S.). We found 1195 articles, removing 377 duplicated records, excluding 780 records based on their titles and abstracts. Two studies were excluded because they included both pediatric and adult patients and data of the two groups were not reported separately, therefore data from adult CD patients could not be extrapolated. For this review, we selected and included 14 articles that reported only data of adult patients with CD on a GFD. The characteristics of the 14 selected studies are reported in Table A1 in Appendix A.

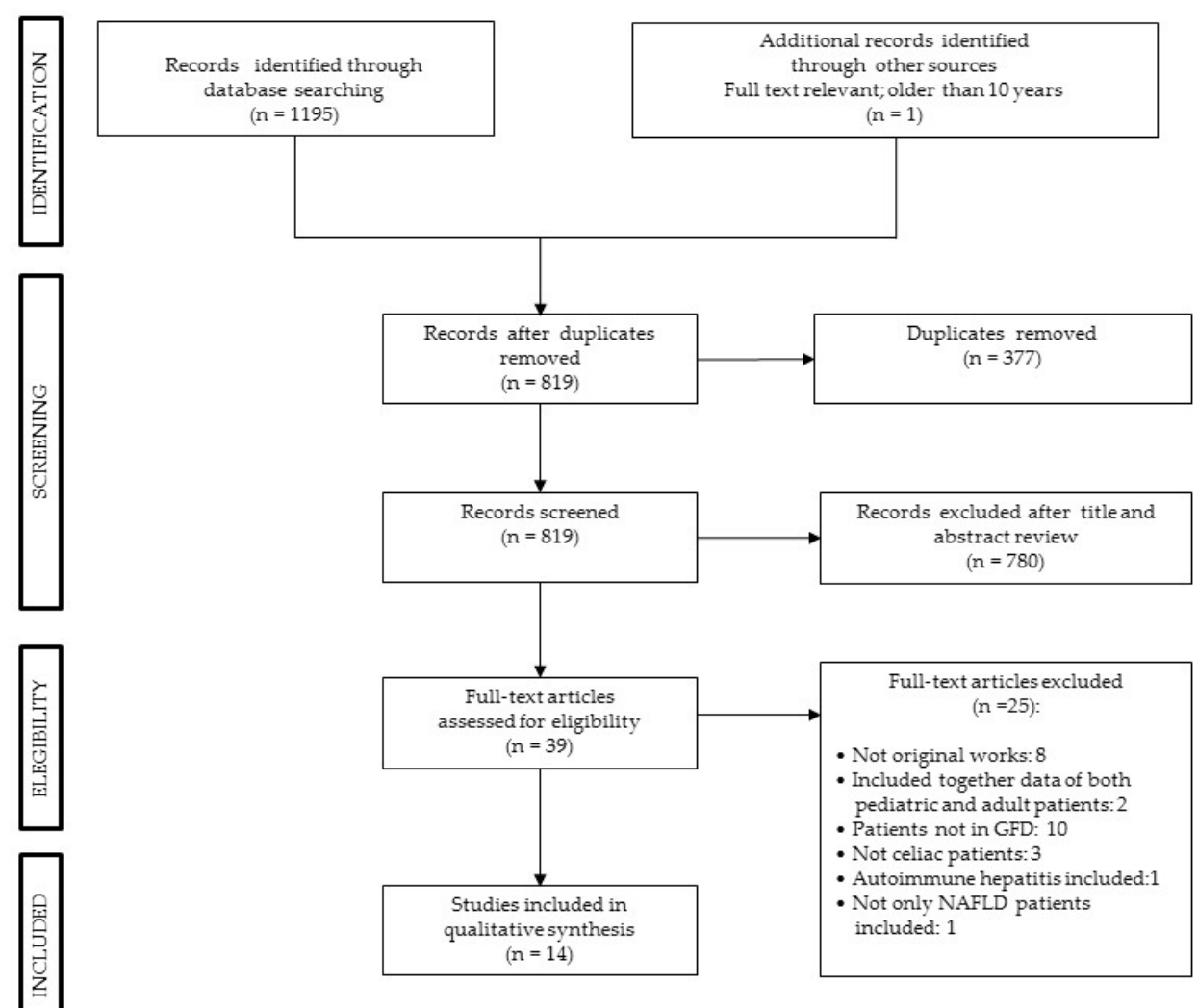

Figure 1. PRISMA flow diagram.

\subsection{Celiac Disease and BMI While on A GFD}

Nine studies assessed the BMI changes in CD patients before and after starting a GFD [4,11,29-35]. Six of these studies analyzed BMI changes as expressed by the mean or median (Table 1) [11,29-33], 
while the remaining three studies evaluated the number of patients with changes in their BMIs in terms of a percentage $[4,34,35]$.

A prospective study including $39 \mathrm{CD}$ patients and 39 controls, with two years of follow-up, showed that patients with a normal BMI $\left(18.5-24.9 \mathrm{Kg} / \mathrm{m}^{2}\right)$ at diagnosis gained weight compared to the control group [29]. However, despite the weight gain, patients with a normal BMI did not move to the overweight or obese groups (BMI $\geq 25 \mathrm{Kg} / \mathrm{m}^{2}$ ), while on the other hand, $50 \%$ of underweight $\left(\mathrm{BMI}<18.5 \mathrm{Kg} / \mathrm{m}^{2}\right.$ ) patients switched to the normal weight group. We note that a potential bias of this study was that these patients were on a Mediterranean-type diet, which is different from a Western diet. The latter is high-calorie diet rich in fats and sugars and can alter gut microbiome composition and metabolic activity [29].

A retrospective study involving 369 CD patients showed that a GFD had a beneficial effect on BMI during the follow-up period [11]. The Authors observed that after starting a GFD, about $60 \%$ of patients with a BMI $<18.5 \mathrm{Kg} / \mathrm{m}^{2}$ gained weight, and $41 \%$ of overweight and obese patients lost weight. However, the majority of patients had a normal BMI at diagnosis, and about $47 \%$ gained weight. They also observed that presentation with diarrhea, being female, and more severe villous atrophy (Marsh IIIb/c) were predictor factors for a low BMI at diagnosis [11].

In a retrospective study of 679 celiac patients on a GFD with a longer follow-up period (mean of 39.5 months; range 1-345), 15.8\% moved from a normal or low BMI class into an overweight class $\left(\mathrm{BMI}>25 \mathrm{~kg} / \mathrm{m}^{2}\right)$ after starting a GFD, and $22 \%$ of overweight patients gained weight after starting a GFD [30]. Overall, the mean BMI increased significantly with a GFD, and in the group of patients with a normal BMI at the beginning of the study, $21.8 \%$ of patients gained weight and increased their BMI by more than two points. A BMI decrease of at least two points was observed in $4.8 \%$ of patients $(p=0.0001)[30]$.

Moreover, an overall increase in BMI after starting a GFD was observed in three other studies (Table 1) [31-33].

In a prospective cohort of 698 patients with a recent diagnosis of $C D$, the changes of BMI were evaluated [34]. In this study, 677 out of 698 patients on a GFD were included in a one-year follow-up: $33 \%$ gained at least $3 \mathrm{~kg}$ and $16 \%$ lost at least the same amount of weight. Notably, $22 \%$ of those who were overweight and $38 \%$ of those with a normal weight gained weight during the follow-up period $(>3 \mathrm{~kg})$. It is important to note that this was a prospective study and therefore it could have induced patients to adopt a more balanced diet and a healthier lifestyle. Finally, weight and height were self-reported, which might have led to an underestimation of BMI [34].

In a retrospective study with a longer follow-up period ( 2 years) that included patients on a GFD with a new diagnosis of $C D, 81 \%$ gained weight, including $82 \%$ of initially overweight patients [4]. In another retrospective study, the number of patients with a BMI $>25 \mathrm{~kg} / \mathrm{m}^{2}$ increased significantly after the initiation of a GFD (45/185 vs. 78/185; $p=0.0001$; follow-up of 7 years; range $1-36$ years) [35].

\subsection{Dyslipidemia in Celiac Disease Following A GFD}

There were three studies found that assessed lipid levels before and after the initiation of a GFD (Table 2) $[32,33,35]$ and one study that reported the prevalence of dyslipidemia in celiac patients on a GFD [22]. In a case-control study, increasing triglyceride blood levels were observed after the diagnosis of CD in patients following a GFD at a follow-up of 4.7 years [33]. In another prospective study, however, the same authors did not find significant changes in the levels of triglycerides (although this was only after a one-year follow-up) [32]. In a retrospective cohort of 185 patients with $C D$, an increase in the prevalence of hypercholesterolemia and a reduction in the high-density lipoprotein (HDL) level was observed; however, the increase in hypertriglyceridemia was not statistically significant $(p=0.339)$ [35]. The Authors reported a worsening of the lipidic profile during the follow-up, which included a higher total cholesterol level, more triglycerides, and a decrease in the HDL level (Table 2) [35]. On the other hand, in a cross-sectional study, the prevalence of dyslipidemia in patients with CD was significantly lower compared to the control group $(18.3 \%$ vs. $34.9 \% ; p<0.0001)$ [22]. 
Table 1. Body mass index (BMI) values of celiac patients before and after starting a gluten-free diet (GFD).

\begin{tabular}{|c|c|c|c|c|c|c|c|c|}
\hline Study (Year) & Study Design & Follow-up Length & BMI Categories & $\begin{array}{l}\text { Number of Patients before } \\
\text { the Start of a GFD N(\%) }\end{array}$ & $\begin{array}{l}\text { Number of Patients after } \\
\text { the Start of a GFD N }(\%)\end{array}$ & BMI before the GFD & BMI after the GFD & $P$-Value \\
\hline Barone et al. (2016) [29] & Prospective cohort & $\begin{array}{c}2.02 \text { years } \\
(1.68-2.9 \text { years })^{* *}\end{array}$ & $\begin{array}{c}\text { Obese } \geq 30 \\
\text { Overweight 25-29.9 } \\
\text { Normal } 18.5-24.9 \\
\text { Underweight }<18.5 \\
\text { Total } \\
\end{array}$ & \begin{tabular}{|c|}
$3(7.7)$ \\
$9(23)$ \\
$23(59)$ \\
$4(10,3)$ \\
$39(100)$ \\
\end{tabular} & $\begin{array}{c}3(7.7) \\
8(20.5) \\
26(66.6) \\
2(5.1) \\
39(100)\end{array}$ & $\begin{array}{c}38(36.2-39.4)^{* *} \\
25.2(25.2-26)^{* *} \\
20.7(20.4-21.7)^{* *} \\
18(17,6-18)^{* *} \\
21.5(20.4-25.1)^{* *}\end{array}$ & $\begin{array}{c}35(33.1-36.7)^{* *} \\
25.2(24.5-26)^{* *} \\
22.5(21.1-23.1)^{* *} \\
18(17.7-18.2)^{* *} \\
22.6(21.1-25.2)^{* *}\end{array}$ & $\begin{array}{c}0.31 \\
0.47 \\
<0.002 \\
0,41 \\
0.07\end{array}$ \\
\hline Cheng et al. (2010) [11] & Retrospective cohort & 2.8 years $(2.7)^{*}$ & $\begin{array}{c}\text { Obese } \geq 30 \\
\text { Overweight 25-29.9 } \\
\text { Normal } 18.5-24.9 \\
\text { Underweight }<18.5 \\
\text { total }\end{array}$ & $\begin{array}{l}25(6.8) \\
56(15.2) \\
224(60.7) \\
64(17.3) \\
369(100) \\
\end{array}$ & $\begin{array}{c}20(6.47) \\
52(16.82) \\
194(62.78) \\
43(13.92) \\
309(100) \\
\end{array}$ & $\begin{array}{l}33.8(3.89)^{*} \\
27.1(1.3)^{*} \\
21.4(1.7)^{*} \\
17.3(0.9)^{*} \\
22.4(4.5)^{*}\end{array}$ & $\begin{array}{l}33.3(3.9)^{*} \\
26.8(2.4)^{*} \\
21.7(2.3)^{*} \\
19(2.7)^{*}\end{array}$ & $<0.0001$ \\
\hline Kabbani et al. (2012) [30] & Retrospective cohort & 3.29 years $(0.08-28.75) *$ & Total & 679 & 679 & $24.0(5.1)$ * & $24.6(5.1)^{*}$ & $<0.001$ \\
\hline Stein et al. (2016) [31] & Case-control & At least 4 weeks & Total & 107 & 107 & $23.8(21.5-27.5)^{* *}$ & $25.1(21.6-28.8)^{* *}$ & $\leq 0.001$ \\
\hline Tortora et al. (2015) [32] & Prospective cohort & 1 year & Total & 98 & 98 & $22.9( \pm 4)^{*}$ & $24.1( \pm 4)^{*}$ & $<0.01$ \\
\hline Tortora et al. (2018) [33] & Case-control & 4.7 years $(1.2)^{*}$ & Total & 370 & 370 & $23.2( \pm 3.6) *$ & $24.8( \pm 3.5) *$ & $<0.001$ \\
\hline
\end{tabular}

Note: * Values are expressed as the mean (SD); ** values are expressed as the median (IQR).

Table 2. Lipid profile in celiac patients before and after GFD.

\begin{tabular}{|c|c|c|c|c|c|c|c|c|c|c|}
\hline \multirow[t]{2}{*}{ Study (Year) } & \multirow[t]{2}{*}{ Study Design } & \multirow[t]{2}{*}{ Follow-up } & \multicolumn{2}{|c|}{ Triglycerides mg/dl } & \multicolumn{2}{|c|}{ Total Cholesterol mg/dl } & \multicolumn{2}{|c|}{ LDL mg/dl } & \multicolumn{2}{|c|}{ HDL mg/dl } \\
\hline & & & Before GFD & After GFD & Before GFD & After GFD & Before GFD & After GFD & Before GFD & After GFD \\
\hline $\begin{array}{c}\text { Tortora (2015) * } \\
{[\text { [32] }}\end{array}$ & Prospective cohort & 1 year & $\begin{array}{c}89.2( \pm 40) \\
(n=98) \\
\text { p: } 0.6\end{array}$ & $\begin{array}{c}92.8( \pm 50) \\
(n=98)\end{array}$ & - & - & - & - & $\begin{array}{c}51.8( \pm 14) \\
(n=98) \\
p: 0.1\end{array}$ & $\begin{array}{c}53.8( \pm 14) \\
(n=98)\end{array}$ \\
\hline $\begin{array}{c}\text { Tortora (2018) * } \\
\text { [33] }\end{array}$ & Case-control & $4.7(\mathrm{SD} \pm 1.2)$ Years & $\begin{array}{c}90.1( \pm 37.8) \\
(n=370)\end{array}$ & $\begin{array}{c}121( \pm 50.3) \\
(n=370)\end{array}$ & $\begin{array}{c}163.7( \pm 35.2) \\
(n=370)\end{array}$ & $\begin{array}{c}179.4( \pm 29.3) \\
(n=370)\end{array}$ & $\begin{array}{c}117.2( \pm 39.1) \\
(n=370)\end{array}$ & $\begin{array}{c}119.8( \pm 38.1) \\
(n=370)\end{array}$ & $\begin{aligned} & 54.4( \pm 13) \\
&(n=370) \\
& \mathrm{F}= 48(27.0-70.0)\end{aligned}$ & $\begin{array}{c}54.2( \pm 12.8) \\
(n=370) \\
\mathrm{F}=35(19-49)\end{array}$ \\
\hline $\begin{array}{c}\text { Ciccone (2019) ** } \\
\text { [35] }\end{array}$ & $\begin{array}{l}\text { Retrospective } \\
\text { cohort }\end{array}$ & 7 years (Range 1-36) & $\begin{array}{c}127.0(60-321) \\
(n=26) p: 0.0006\end{array}$ & $\begin{array}{c}163.0(151-332) \\
(n=26)\end{array}$ & $\begin{array}{c}191(90.0-322) \\
(n=88) p: 0.0001\end{array}$ & $\begin{array}{c}228(201-33) \\
(n=88)\end{array}$ & - & - & $\begin{array}{l}(n=70) p: 0.0001 \\
\mathrm{M}=52(34.0-67.0) \\
(n=16) p: 0.0001\end{array}$ & $\begin{array}{c}(n=70) \\
\mathrm{M}=33(26-59) \\
(n=16)\end{array}$ \\
\hline
\end{tabular}

Note: CD, Celiac Disease; GFD: Gluten-free diet; SD, Standard Deviation * Mean $( \pm$ SD); ** Median (Range). 


\subsection{Celiac Disease Following A GFD and Type 2 Diabetes Mellitus}

There were two studies found that assessed the prevalence of T2DM in CD patients on a GFD (Table 3) [22,36], and two studies examined the glycemia level before and after the start of a GFD [32,33].

Table 3. The prevalence of type 2 diabetes (age $\geq 30$ years) in celiac disease and control groups.

\begin{tabular}{ccccc}
\hline Study (Year) & Study Design & CD Group N (\%) & Control Group N (\%) & P-Value \\
\hline Kabbani et al. (2013) [22] & Cross-sectional & $26 / 840(3.1)$ & $81 / 840(9.60)$ & $<0.0001$ \\
Reilly et al. (2015) [36] & Prospective cohort & $818 / 26,816(3.1)$ & $3919 / 130,051(3)$ & - \\
\hline
\end{tabular}

Note: $C D$, celiac disease.

In a cross-sectional study involving $840 \mathrm{CD}$ patients and 840 healthy subjects, the prevalence of T2DM was three times lower in the celiac group than in the matched control and in the general population [22]. Furthermore, CD patients had a lower BMI $\left(24.7\right.$ vs. $\left.27.5 \mathrm{Kg} / \mathrm{m}^{2} ; p<0.0001\right)$. The incidence of T2DM seemed to not be influenced by the duration of the GFD. In fact, in patients that were on a GFD for less than two years, the prevalence of T2DM was not statistically different from the prevalence in those on a GFD for more than two years, despite the fact that the patients on the GFD for longer were older $(1.4 \%$ vs. $3.3 \% ; p=.7)$ (Table 3$)$. Whether a lower BMI in celiac patients is a protective factor for the incidence of T2DM is not clear, the mechanisms by which patients with CD had lower prevalence of T2DM are not clear, however this finding could be attributable to altered pancreatic function, impaired nutrient absorption, and changes in gastrointestinal endocrine functioning. Furthermore, tissue transglutaminase drives inflammation in $C D$, impairing the expression of peroxisome proliferator-activated receptor $\gamma$, which could be implicated in a decreased risk of T2DM [22].

In a large population-based cohort of 26,816 patients with $\mathrm{CD}$ and 130,051 controls the prevalence of T2DM found in celiac patients on a GFD was the same of that observed in matched reference individuals (Table 3) [36]. A critical point of this study is the control group of patients including a very different population.

With regard to glycemia levels, a prospective study showed significant differences at $\mathrm{CD}$ diagnosis and follow up [32]. Of the included 98 patients with $C D, 7$ patients $(7.1 \%)$ at $C D$ diagnosis versus 25 patients $(25.5 \%)$ after starting GFD had blood glucose levels which exceeded the threshold $(p<0.01$, OR 3.7). The mean glycemic value after 1 year of GFD was $92 \mathrm{mg} / \mathrm{dL}$ versus $86 \mathrm{mg} / \mathrm{dL}$ at CD diagnosis [32]. In another case-control study, the same Authors reported an increase in the fasting blood glucose levels after the start of a GFD compared with those at CD diagnosis (mean \pm SD: $88.7 \pm 13.4 \mathrm{mg} / \mathrm{dL}$ vs. $84.1 \pm 19.8 \mathrm{mg} / \mathrm{dL}$, respectively) [33].

\subsection{Celiac Disease Following $a$ GFD and NAFLD}

There were four studies found that assessed the frequency of NAFLD/NASH before and after the start of a GFD (Table 4) [35-38]. Three of them evaluated any predictive factors that could increase metabolic risk during the GFD $[19,33,38]$.

In a prospective study, patients with celiac disease had a major risk of developing NAFLD compared to the general population [36]. The risk was highest in the first year after diagnosis and was persistently higher than in the general population over the next 15 years. This work involved a cohort of 26,861 patients with CD with no signs of liver disease at diagnosis (and no history of alcohol-related disorders). This cohort was compared to a group of 130,051 healthy control patients from the Swedish national registry. The risk of developing NAFLD in celiac patients was significantly elevated compared to the general population. The hazard ratio (HR) was higher in the first year after celiac disease diagnosis, with a 4.2-fold increase in the first 5 years, and was significantly higher in the male population (male $4.5,95 \% \mathrm{CI}=2.7-7.6$ vs. female $2.1,95 \% \mathrm{CI}=1.3-3.2$ ) (Table 4 ) [36]. 
Table 4. Diagnosis of nonalcoholic fatty liver disease (NAFLD) and hepatic steatosis (HS) in celiac patients on a GFD.

\begin{tabular}{|c|c|c|c|c|c|}
\hline Study (Year) & Study Design & Follow-up & NAFLD/Celiac Disease & $\begin{array}{l}\text { NAFLD/Healthy } \\
\text { Control }\end{array}$ & OR, HR, $P$-Value \\
\hline Reilly et al. (2015) * [36] & Prospective cohort & $11.4 \pm 6.4$ years & $\begin{array}{c}53 / 26861 \\
(21 / 100.00)+\end{array}$ & $\begin{array}{c}85 / 130051 \\
(6 / 100.000)+\end{array}$ & $\begin{array}{c}\mathrm{HR}=2.8(2.0-3.8 ; \\
\quad p<0.001) \\
\mathrm{OR}=2.90\end{array}$ \\
\hline Tovoli et al. (2018) [37] & Case-control & - & $70 / 202(34.7 \%)$ & $44 / 202(21.8 \%)$ & $\begin{array}{l}\quad(\mathrm{CI}: 1.64-5.15 \\
\quad p<0.001)\end{array}$ \\
\hline Study (Year) & Study Design & $\begin{array}{c}\text { Follow-up } \\
\text { Years * (Range) }\end{array}$ & $\begin{array}{l}\text { HS/Celiac Disease } \\
\text { before GFD }\end{array}$ & $\begin{array}{c}\text { HS/Celiac Disease after } \\
\text { GFD }\end{array}$ & $P$-Value \\
\hline Ciccone et al. (2019) ${ }^{* *}[35]$ & Retrospective cohort & $7(1-36)$ years & $3 / 185(1.7 \%)$ & $20 / 185(11.1 \%)$ & $p<0.0001$ \\
\hline Imperatore et al. $(2018) *[38]$ & Prospective cohort & 1 years & $78 / 301(25.9 \%)$ & $112 / 301(37.2 \%)$ & $p<0.01$ \\
\hline
\end{tabular}

Note: CD: celiac disease; NAFLD: nonalcoholic fatty liver disease; HS: hepatic steatosis; HR: hazard ratio; OR: odds ratio; HS: hepatic steatosis; ${ }^{*}($ mean $\pm \mathrm{SD}) ;{ }^{* *}$ median; + person years.

Similar results were reported in a case-control study involving 202 patients with CD on a GFD for at least six months [37]. Patients with CD were compared to control patients matched based on demographic characteristics (age and gender) and metabolic risk factors (BMI, Diabetes Mellitus, triglycerides, and cholesterol). The prevalence of NAFLD was significantly higher in the celiac population $(34.7 \%)$ compared to the controls $(21.8 \%)(p=0.006)$. Binary logistic regression confirmed an increased risk of NAFLD in patients with CD (adjusted OR $=2.904 ;$ CI 1639-5146; $p<0.001$ ). The authors also observed that the raw prevalence of NAFLD in CD patients with normal weight was even higher than in the general population ( $20 \%$ vs. $5.8 \%$, respectively; $p<0.001)$. The multiple logistic regression also showed a higher relative risk for NAFLD in these celiac subjects with a normal weight (adjusted OR 5.713; CI 2300-14194; $p<0.001$ ). On the other hand, in the overweight population $\left(B M I>25 \mathrm{~kg} / \mathrm{m}^{2}\right)$, the prevalence of NAFLD in the CD patients and controls was not significantly different $(67.8 \%$ vs. $55.4 \% ; p=0.202)$. The Authors suggested that traditional risk factors could influence the occurrence of NAFLD in celiac subjects, as they do in the general population. On the other hand, the celiac patients developed NAFLD even when they had fewer risk factors than the general population. Therefore, the effect of a GFD on the pathogenesis of liver damage could have been underestimated [37].

In a retrospective cohort of 185 patients with CD, the incidence of hepatic steatosis (HS) in celiac patients at diagnosis and during follow-up was assessed [35]. HS was found by ultrasound in three patients $(1.6 \%)$ at CD diagnosis. At the end of the follow-up period (median $=7$ years; range $1-36$ ), the prevalence of HS $(n=20 ; 11.0 \%)$ was significantly higher than at the time of CD diagnosis $(1.6 \%)$ $(p<0.001)[35]$.

A prospective study involving 301 patients on a GFD showed the same results. The Authors observed that 112 out of 301 (37.2\%) patients developed HS over a one-year follow-up period [38] (Table 4).

In a large prospective longitudinal study, the frequency of CD among NAFLD patients and clinicopathological pattern and outcome was assessed [19]. CD was found in $7.2 \%$ of patients with NAFLD. The concomitant presence of CD and NAFLD showed a high degree of intestinal damage at diagnosis. Patients with concomitant CD and NAFLD achieved similar clinical improvement after adherence to GFD. However, intestinal histological improvement was less and delayed in patients with concomitant CD and NAFLD. Moreover, at the end of the follow-up period, more patients with concomitant NAFLD and CD progressed to NASH than patients with NAFLD alone. Therefore, the authors suggested that the two diseases had a negative impact on each other [19].

Finally, in a prospective cohort of 301 patients with CD, predictive factors for metabolic syndrome (MS) and HS in patient with CD after 1 year of GFD were evaluated [38]. Of the 301 CD patients, $4.3 \%$ met the criteria for MS diagnosis and $25.9 \%$ showed HS at the time of CD diagnosis. After 1 year of GFD, $23.9 \%$ developed MS (4.3\% versus $23.9 \%$; $p<0.001$; OR 6.9 ) and 37.2 developed HS (25.9\% vs. $37.2 \% ; p<0.01$; OR 1.69). At multivariate analysis, high BMI at CD diagnosis (OR 10.8; $p<0.001$ ) and use of proton pump inhibitors (PPIs) (OR 22.9; $p<0.001)$ were the only factors associated with the 
occurrence of MS. Insulin resistance (OR 9.7; $p<0.001$ ) and PPIs exposure (OR 9.2; $p<0.001$ ) were the only factors associated with the development of HS [38].

\section{Discussion}

The studies included in this review showed an increased prevalence and incidence of NAFLD and weight gain, a worse lipid profile, and high blood glucose levels, suggesting that important changes occur in celiac patients on a GFD [4,11,19,22,29-38].

The mechanisms leading both CD and GFD to the metabolic alterations such as the increase in body weight and BMI, blood triglyceride and cholesterol levels and blood glucose levels, as well as the development of NAFLD, remain to be clarified. These metabolic alterations could be due either to the increase in nutrient absorption processes after the start of GFD or to the consumption of a high-calorie diet rich in fats and simple carbohydrates (sugars). The regression of inflammation and atrophy of the gut mucosa induced by GFD can led to a marked improvement of intestinal absorption of nutrients in subjects who are in a compensatory hyperphagic status [32]. This is indirectly confirmed by the fact that in patients with $\mathrm{CD}$ a more severe degree of villous atrophy and the concomitant diarrhea were independent predictors for a lower BMI [11]. Non-adherence to the GFD appears to contribute to weight loss, while adherence may be an important factor in determining weight gain in CD patients. In addition, the duration on GFD was found to be a possible variable affecting changes in BMI [30].

Several studies demonstrated that GFD, although it is the only available treatment for CD, has potentially negative effects on nutritional and metabolic status [33,39]. A British study reported that female CD patients consumed significantly more energy from all macronutrients when compared with a nonceliac population, attributing this to higher intake of sweet snacks that were richer in saturated fat [40]. CD patients also had significantly lower intakes of fibers.

There is evidence that GFD can determine a higher intake of simple sugars, proteins and saturated fat and a lower intake of complex carbohydrates and fibers [32,41]. In patients with CD on a GFD, a higher intake of lipids as compared with controls was found, confirming that long-term GFD may not be nutritionally balanced $[29,42,43]$. In addition, many gluten-free foods are characterized by a higher glycemic index than that of equivalent gluten-containing foods $[27,44]$. It is probable that the absence of gluten on the one hand increases the amylase's ability to digest starch in the gut lumen, therefore increasing starch absorption, and on the other determines the unpalatability of some gluten-free foods, then inducing a preference towards hyperproteic and hyperlipidemic foods $[29,41,45]$.

In patients with CD on a GFD, both the increase in nutrient absorption (as a result of the improvement of the atrophy of the gut mucosa) and the intake of higher calories, fats and simple carbohydrates could contribute to the worsening of the metabolic status and to the increase of the prevalence of NAFLD in these patients [36,37].

Recent evidence has suggested that, despite a lifelong gluten-free diet, some disorders can persist, e.g., increased gut permeability, small bowel overgrowth, microbiota changes, exocrine pancreatic insufficiency, and low-grade gastrointestinal inflammation [46-49]. Some of these disorders could be responsible for the development of NAFLD. Of these factors, the most studied was the mucosal barrier, in particular the intestinal permeability.

Several studies have shown that intestinal permeability may play a role in the pathogenesis of NAFLD [50]. In fact, some endotoxins, such as lipopolysaccharides (common endotoxins of gut bacteria), could reach the liver and trigger an immune reaction through the "Tall-like receptors" [51]. The reduction in the incidence of NAFLD/NASH after the start of a GFD could be related to the improvement of gut mucosal inflammation, atrophy, and permeability induced by the diet. Whether a compromised intestinal barrier is a cause or effect of NAFLD requires additional study, though the prevailing theory is that bacteria derived endotoxin and related cytokines may play a central role in the evolution of liver steatosis in NASH. Furthermore, in addition to the previously described mechanisms, a gluten-free diet itself could have a role. In the last few years, the nutritional profile of gluten-free food products has been increasingly questioned within the scientific community. The nutritional quality of 
the gluten-free food products currently available on the market is inadequate -low protein contents and high fat, sugar and salt contents-compared to equivalent gluten-containing products [52-54]. Data from studies on gluten-free foods have indicated that there is a need to lower fat and calories and to include more fibers, proteins, electrolytes, vitamins, and other micronutrients. Another important factor that is usually not taken into consideration is the market for gluten-free foods and the economic strength of CD patients. Gluten-free food availability has increased in most markets, especially in more expensive ones. The lower availability and quality of the gluten-free foods sold in cheaper markets could disproportionately impact poor socioeconomic cohorts [55]. Finally, a hyperphagic compensatory status usually follows malabsorption disorders and induces weight gain [37].

All of the above-mentioned factors could contribute to the development of NAFLD in CD patients on a gluten-free diet. It is important to underline that NAFLD is considered to be a potential hepatic expression of MS [35]. MS involves interrelated risk factors for cardiovascular disease and diabetes. These factors include hypertension, low HDL cholesterol levels, elevated triglyceride levels, diabetes/insulin resistance, and central adiposity. The pathophysiology of these conditions is unclear, but several hypotheses have been proposed.

Most studies in the literature have shown that CD patients (at diagnosis) have a lower BMI than the general population [10-12]; therefore, weight gain from a GFD may have positive effects on these patients. However, it has been clearly demonstrated that nowadays, an increasing number of $C D$ patients present with a normal or high BMI at the time of diagnosis [3-9].

It is important to underline that, despite improvements in body weight (weight gain in underweight patients and weight loss in overweight patients), patients with a normal weight usually gain weight. In fact, an increase in the average BMI was observed in all studies found (Table 1) [19-21,35-37]. In patients with CD on a GFD, the increase in BMI is probably linked to the increased intake of calories, fats and simple carbohydrates, but probably also to reduced physical activity. More than half of women with celiac disease frequently report low physical activity both before and after a GFD [56]. The reduced physical activity could be linked to the chronic fatigue which is a common finding in patients with CD, which ameliorates with the GFD [57]. Increased body weight and BMI can represent a risk factor for both NAFLD and T2DM.

Therefore, the global epidemic of obesity and NAFLD, increased BMI values at CD diagnosis, and the impact of a GFD on the metabolic status of these patients could be important and could change historical concepts of the malnutrition status of celiac patients.

T2DM per se does not appear to be increased in patients with CD compared with controls. Only in two studies, a higher prevalence of hyperglycaemia was reported in patients with CD after GFD compared to that observed at CD diagnosis. In none of these studies the current criteria for the diagnosis of T2DM had been specified and adopted; diabetes may be diagnosed based on plasma glucose criteria, either the fasting plasma glucose (FPG) value or the 2-h plasma glucose (2-h PG) value during a 75-g oral glucose tolerance test (OGTT), or HbA1C criteria [58]. Therefore, GFD would appear to induce only a slight increase in fasting blood glucose levels, but not a real increase in the prevalence of T2DM. In some cases the diagnosis of T2DM was made before the CD diagnosis, therefore GFD had no role in the development of diabetes [22].

Although NAFLD and T2DM are often found together in adults, in patients with CD the increase in prevalence in NAFLD not associated with diabetes can be detected [35-38]; at most NAFLD seems to be associated only with a slight increase in fasting blood glucose levels [32,33].

The incidence of T2DM is known to increase with age and BMI, and is linked closely to both diet and ethnicity. The increase in body weight and BMI seen in patients with CD after GFD could theoretically be a risk factor for both NAFLD and for T2DM, but the latter does not seem to be increased in the CD, either at diagnosis or after GFD [22,36].

NAFLD has been predominantly linked to obesity, dyslipidemia, and insulin resistance, although NAFLD can occur in those with a normal BMI. However, an insulin resistance condition has not been reported in CD patients, neither at diagnosis nor after GFD. 
A GFD alters certain cardiovascular risk factors in CD patients, but the overall effect on cardiovascular risk in individuals remains unclear [59]. Therefore, it is important to explore the relationship between $\mathrm{CD}$ and cardiovascular disease.

In a systematic review with meta-analysis, increased risk of stroke (OR 1.11; 95\% CI 1.02-1.20; $p=0.316$ ) in CD patients was reported, whereas a statistically significant increased risk of myocardial infarction and cardiovascular death was not found [60].

Moreover, a study done on a UK population did not reveal an increased risk of cardiovascular death in celiac patients compared to the general population (standardized mortality ratio: 1.23 ; $95 \% \mathrm{CI}$ 0.98-1.51). However, the standardized mortality ratio was greater during the post-diagnosis period (after 2 years) than during the peri-diagnosis period (within 2 years) in CD patients [61].

In conclusion, taking into account the worse lipid profiles, the increases in new diagnoses of NAFLD, and the weight gain seen in CD patients (in particular in normal/overweight celiac patients), celiac patients need to be informed about these potential risks and counseled on personalized nutrition after starting a GFD.

Despite a GFD being the only effective treatment available for celiac disease-and despite it playing a key role in mucosal healing and the remission of symptoms-liver functioning, body weight, and nutritional profiles should be monitored for the duration of a GFD.

Author Contributions: M.V., S.L., and G.S. performed the literature review, wrote the manuscript, and prepared the Figure and Tables; A.V. wrote and reviewed the manuscript and suggested important research points; G.F. reviewed the manuscript and provided critical comments; G.L. suggested the topic of the review and supervised, wrote, and critically reviewed the manuscript. All authors have read and agreed to the published version of the manuscript.

Funding: No financial support was received for this study.

Conflicts of Interest: The authors have no conflicts of interest to declare and did not use any outside assistance in preparing the manuscript.

\section{Appendix A}

Table A1. Baseline characteristics of the included studies.

\begin{tabular}{|c|c|c|c|c|c|}
\hline Study & Study Design & Patients & Age & Control Group & $\begin{array}{l}\text { Clinical and Metabolic } \\
\text { Findings Assessed }\end{array}$ \\
\hline Barone et al. (2016), Italy [29] & Prospective cohort & patients with $\mathrm{CD}(N: 39)$ & $\geq 18$ & 39 & BMI \\
\hline Cheng et al. (2010), USA [11] & Retrospective cohort & patients with $\mathrm{CD}(\mathrm{N}: 369)$ & $\geq 18$ & not any & BMI \\
\hline Stein et al. (2016), USA [31] & Case-control & patients with $\mathrm{CD}(\mathrm{N}: 174)$ & $\geq 17$ & 696 & BMI \\
\hline Tortora et al. (2015), Italy [32] & Prospective cohort & patients with $\mathrm{CD}(\mathrm{N}: 98)$ & $\geq 18$ & not any & $\begin{array}{l}\text { BMI, dyslipidemia, } \\
\text { T2DM }\end{array}$ \\
\hline Tortora et al. (2018), Italy [33] & Case-control & patients with CD (N:136) & $\geq 18$ & $\begin{array}{c}C D \text { without } H S(N \text { : } \\
\text { 234) }\end{array}$ & $\begin{array}{l}\text { BMI, dyslipidemia, } \\
\text { T2DM }\end{array}$ \\
\hline Dickey et al. (2006), UK [4] & Retrospective cohort & patients with CD (N:371) & $\geq 18$ & not any & BMI \\
\hline Ciccone et al. (2019), Italy [35] & Retrospective cohort & patients with CD (N:185) & $\geq 18$ & not any & BMI, dyslipidemia, HS \\
\hline Kabbani et al. (2013), USA [22] & Cross-sectional & patients with $\mathrm{CD}(\mathrm{N}: 840)$ & $\geq 18$ & 840 & Dyslipidemia, T2DM \\
\hline Reilly et al. (2015), Sweden [36] & Prospective cohort & patients with $\mathrm{CD}(\mathrm{N}: 26,816)$ & $\geq 18$ & 130,051 & T2DM, NAFLD \\
\hline Tovoli et al. (2018), Italy [37] & Case-control & patients with CD $(N: 2020)$ & $\geq 18$ & 202 & NAFLD \\
\hline Imperatore et al. (2018), Italy [38] & Prospective cohort & patients with $\mathrm{CD}(\mathrm{N}: 301)$ & $\geq 18$ & GERD $(N: 50)$ & HS \\
\hline
\end{tabular}

Note: CD, celiac disease; GFD, gluten-free diet; BMI, body mass index; HS, hepatic steatosis; T2DM, type 2 diabetes mellitus; GERD, gastroesophageal reflux disease; NAFLD, Nonalcoholic fatty liver disease.

\section{References}

1. Ludvigsson, J.F.; Leffler, D.A.; Bai, J.C.; Biagi, F.; Fasano, A.; Green, P.H.R.; Hadjivassiliou, M.; Kaukinen, K.; Kelly, C.P.; Leonard, J.N.; et al. The Oslo definitions for coeliac disease and related terms. Gut 2013, 62, 43-52. [CrossRef] [PubMed]

2. Ludvigsson, J.F.; Bai, J.C.; Biagi, F.; Card, T.R.; Ciacci, C.; Ciclitira, P.J.; Green, P.H.R.; Hadjivassiliou, M.; Holdoway, A.; van Heel, D.A.; et al. Diagnosis and management of adult coeliac disease: Guidelines from the British Society of Gastroenterology. Gut 2014, 63, 1210-1228. [CrossRef] [PubMed] 
3. Newnham, E.D. Coeliac disease in the 21st century: Paradigm shifts in the modern age: Shifting treatment paradigms in coeliac disease. J. Gastroenterol. Hepatol. 2017, 32, 82-85. [CrossRef] [PubMed]

4. Dickey, W.; Kearney, N. Overweight in Celiac Disease: Prevalence, Clinical Characteristics, and Effect of a Gluten-Free Diet. Am. J. Gastroenterol. 2006, 101, 2356-2359. [CrossRef] [PubMed]

5. Singh, I.; Agnihotri, A.; Sharma, A.; Verma, A.K.; Das, P.; Thakur, B.; Sreenivas, V.; Gupta, S.D.; Ahuja, V.; Makharia, G.K. Patients with celiac disease may have normal weight or may even be overweight. Indian J. Gastroenterol. 2016, 35, 20-24. [CrossRef] [PubMed]

6. Dominguez Castro, P.; Harkin, G.; Hussey, M.; Christopher, B.; Kiat, C.; Liong Chin, J.; Trimble, V.; McNamara, D.; MacMathuna, P.; Egan, B.; et al. Changes in Presentation of Celiac Disease in Ireland From the 1960s to 2015. Clin. Gastroenterol. Hepatol. 2017, 15, 864-871. [CrossRef]

7. Tucker, E.; Rostami, K.; Prabhakaran, S.; Al Dulaimi, D. Patients with coeliac disease are increasingly overweight or obese on presentation. J. Gastrointest. Liver Dis. 2012, 21, 11-15.

8. Olén, O.; Montgomery, S.M.; Marcus, C.; Ekbom, A.; Ludvigsson, J.F. Coeliac disease and body mass index: A study of two Swedish general population-based registers. Scand. J. Gastroenterol. 2009, 44, 1198-1206. [CrossRef]

9. Villanueva, M.; Oyarzún, A.; Leyton, B.; González, M.; Navarro, E.; Canales, P.; Ossa, C.; Muñoz, M.P.; Bascuñán, K.A.; Araya, M. Changes in Age at Diagnosis and Nutritional Course of Celiac Disease in the Last Two Decades. Nutrients 2020, 12, 156. [CrossRef]

10. Castillo, N.E.; Vanga, R.R.; Theethira, T.G.; Rubio-Tapia, A.; Murray, J.A.; Villafuerte, J.; Bonder, A.; Mukherjee, R.; Hansen, J.; Dennis, M.; et al. Prevalence of Abnormal Liver Function Tests in Celiac Disease and the Effect of a Gluten-Free Diet in the US Population. Am. J. Gastroenterol. 2015, 110, 1216-1222. [CrossRef]

11. Cheng, J.; Brar, P.S.; Lee, A.R.; Green, P.H.R. Body Mass Index in Celiac Disease: Beneficial Effect of a Gluten-free Diet. J. Clin. Gastroenterol. 2010, 44, 267-271. [CrossRef] [PubMed]

12. NCD Risk Factor Collaboration (NCD-RisC). Trends in adult body-mass index in 200 countries from 1975 to 2014: A pooled analysis of 1698 population-based measurement studies with $19 \cdot 2$ million participants. Lancet Lond. Engl. 2016, 387, 1377-1396. [CrossRef]

13. Cichewicz, A.B.; Mearns, E.S.; Taylor, A.; Boulanger, T.; Gerber, M.; Leffler, D.A.; Drahos, J.; Sanders, D.S.; Thomas Craig, K.J.; Lebwohl, B. Diagnosis and Treatment Patterns in Celiac Disease. Dig. Dis. Sci. 2019, 64, 2095-2106. [CrossRef] [PubMed]

14. Hoffmanová, I.; Sánchez, D.; Tučková, L.; Tlaskalová-Hogenová, H. Celiac Disease and Liver Disorders: From Putative Pathogenesis to Clinical Implications. Nutrients 2018, 10, 892. [CrossRef] [PubMed]

15. Sainsbury, A.; Sanders, D.S.; Ford, A.C. Meta-analysis: Coeliac disease and hypertransaminasaemia: Meta-analysis: Coeliac disease and hypertransaminasaemia. Aliment. Pharmacol. Ther. 2011, 34, 33-40. [CrossRef] [PubMed]

16. Korpimäki, S.; Kaukinen, K.; Collin, P.; Haapala, A.M.; Holm, P.; Laurila, K.; Kurppa, K.; Saavalainen, P.; Haimila, K.; Partanen, J.; et al. Gluten-sensitive hypertransaminasemia in celiac disease: An infrequent and often subclinical finding. Am. J. Gastroenterol. 2011, 106, 1689-1696. [CrossRef]

17. Hagander, B.; Berg, N.O.; Brandt, L.; Nordén, A.; Sjölund, K.; Stenstam, M. Hepatic injury in adult coeliac disease. Lancet 1977, 310, 270-272. [CrossRef]

18. Younossi, Z.M.; Koenig, A.B.; Abdelatif, D.; Fazel, Y.; Henry, L.; Wymer, M. Global epidemiology of nonalcoholic fatty liver disease-Meta-analytic assessment of prevalence, incidence, and outcomes. Hepatology 2016, 64, 73-84. [CrossRef]

19. Kamal, S.; Aldossari, K.K.; Ghoraba, D.; Abdelhakam, S.M.; Kamal, A.H.; Bedewi, M.; Nabegh, L.; Bahnasy, K.; Hafez, T. Clinicopathological and immunological characteristics and outcome of concomitant coeliac disease and non-alcoholic fatty liver disease in adults: A large prospective longitudinal study. BMJ Open Gastroenterol. 2018, 5, e000150.

20. Bakhshipour, A.; Kaykhaei, M.A.; Moulaei, N.; Mashhadi, M.A. Prevalence of coeliac disease in patients with non-alcoholic fatty liver disease. Arab J. Gastroenterol. Off. Publ. Pan-Arab Assoc. Gastroenterol. 2013, 14, 113-115. [CrossRef] 
21. Rahimi, A.R.; Daryani, N.E.; Ghofrani,H.; Taher, M.; Pashaei, M.R.; Abdollahzade, S.; Kalani, M.; Ajdarkosh, H. The prevalence of celiac disease among patients with non-alcoholic fatty liver disease in Iran. Turk. J. Gastroenterol. Off. J. Turk. Soc. Gastroenterol. 2011, 22, 300-304. [CrossRef] [PubMed]

22. Kabbani, T.A.; Kelly, C.P.; Betensky, R.A.; Hansen, J.; Pallav, K.; Villafuerte-Gálvez, J.A.; Vanga, R.; Mukherjee, R.; Novero, A.; Dennis, M.; et al. Patients with celiac disease have a lower prevalence of non-insulin-dependent diabetes mellitus and metabolic syndrome. Gastroenterology 2013, 144, 912-917. [CrossRef] [PubMed]

23. Kylökäs, A.; Kaukinen, K.; Huhtala, H.; Collin, P.; Mäki, M.; Kurppa, K. Type 1 and type 2 diabetes in celiac disease: Prevalence and effect on clinical and histological presentation. BMC Gastroenterol. 2016, 16, 76. [CrossRef]

24. West, J.; Logan, R.F.A.; Card, T.R.; Smith, C.; Hubbard, R. Risk of vascular disease in adults with diagnosed coeliac disease: A population-based study. Aliment. Pharmacol. Ther. 2004, 20, 73-79. [CrossRef] [PubMed]

25. Babio, N.; Alcázar, M.; Castillejo, G.; Recasens, M.; Martínez-Cerezo, F.; Gutiérrez-Pensado, V.; Masip, G.; Vaqué, C.; Vila-Martí, A.; Torres-Moreno, M.; et al. Patients with Celiac Disease Reported Higher Consumption of Added Sugar and Total Fat Than Healthy Individuals. J. Pediatr. Gastroenterol. Nutr. 2017, 64, 63-69. [CrossRef] [PubMed]

26. Segura, M.E.M.; Rosell, C.M. Chemical composition and starch digestibility of different gluten-free breads. Plant Foods Hum. Nutr. Dordr. Neth. 2011, 66, 224-230. [CrossRef] [PubMed]

27. Jenkins, D.J.; Thorne, M.J.; Wolever, T.M.; Jenkins, A.L.; Rao, A.V.; Thompson, L.U. The effect of starch-protein interaction in wheat on the glycemic response and rate of in vitro digestion. Am. J. Clin. Nutr. 1987, 45, 946-951. [CrossRef] [PubMed]

28. Berti, C.; Riso, P.; Monti, L.D.; Porrini, M. In vitro starch digestibility and in vivo glucose response of gluten-free foods and their gluten counterparts. Eur. J. Nutr. 2004, 43, 198-204. [CrossRef]

29. Barone, M.; Della Valle, N.; Rosania, R.; Facciorusso, A.; Trotta, A.; Cantatore, F.P.; Falco, S.; Pignatiello, S.; Viggiani, M.T.; Amoruso, A.; et al. A comparison of the nutritional status between adult celiac patients on a long-term, strictly gluten-free diet and healthy subjects. Eur. J. Clin. Nutr. 2016, 70, 23-27. [CrossRef]

30. Kabbani, T.A.; Goldberg, A.; Kelly, C.P.; Pallav, K.; Tariq, S.; Peer, A.; Hansen, J.; Dennis, M.; Leffler, D.A. Body mass index and the risk of obesity in coeliac disease treated with the gluten-free diet. Aliment. Pharmacol. Ther. 2012, 35, 723-729. [CrossRef]

31. Stein, A.C.; Liao, C.; Paski, S.; Polonsky, T.; Semrad, C.E.; Kupfer, S.S. Obesity and Cardiovascular Risk in Adults With Celiac Disease. J. Clin. Gastroenterol. 2016, 50, 545-550. [CrossRef] [PubMed]

32. Tortora, R.; Capone, P.; De Stefano, G.; Imperatore, N.; Gerbino, N.; Donetto, S.; Monaco, V.; Caporaso, N.; Rispo, A. Metabolic syndrome in patients with coeliac disease on a gluten-free diet. Aliment. Pharmacol. Ther. 2015, 41, 352-359. [CrossRef]

33. Tortora, R.; Rispo, A.; Alisi, A.; Imperatore, N.; Crudele, A.; Ferretti, F.; Nobili, V.; Miele, L.; Gerbino, N.; Caporaso, N.; et al. PNPLA3 rs738409 Polymorphism Predicts Development and Severity of Hepatic Steatosis but Not Metabolic Syndrome in Celiac Disease. Nutrients 2018, 10, 1239. [CrossRef] [PubMed]

34. Ukkola, A.; Mäki, M.; Kurppa, K.; Collin, P.; Huhtala, H.; Kekkonen, L.; Kaukinen, K. Changes in body mass index on a gluten-free diet in coeliac disease: A nationwide study. Eur. J. Intern. Med. 2012, 23, 384-388. [CrossRef] [PubMed]

35. Ciccone, A.; Gabrieli, D.; Cardinale, R.; Di Ruscio, M.; Vernia, F.; Stefanelli, G.; Necozione, S.; Melideo, D.; Viscido, A.; Frieri, G.; et al. Metabolic Alterations in Celiac Disease Occurring after Following a Gluten-Free Diet. Digestion 2019, 100, 262-268. [CrossRef] [PubMed]

36. Reilly, N.R.; Lebwohl, B.; Hultcrantz, R.; Green, P.H.R.; Ludvigsson, J.F. Increased risk of non-alcoholic fatty liver disease after diagnosis of celiac disease. J. Hepatol. 2015, 62, 1405-1411. [CrossRef] [PubMed]

37. Tovoli, F.; Negrini, G.; Farì, R.; Guidetti, E.; Faggiano, C.; Napoli, L.; Bolondi, L.; Granito, A. Increased risk of nonalcoholic fatty liver disease in patients with coeliac disease on a gluten-free diet: Beyond traditional metabolic factors. Aliment. Pharmacol. Ther. 2018, 48, 538-546. [CrossRef]

38. Imperatore, N.; Tortora, R.; Testa, A.; Gerbino, N.; Caporaso, N.; Rispo, A. Erratum to: Proton pump inhibitors as risk factor for metabolic syndrome and hepatic steatosis in coeliac disease patients on gluten-free diet. J. Gastroenterol. 2018, 53, 578. [CrossRef] 
39. Bascuñán, K.A.; Vespa, M.C.; Araya, M. Celiac disease: Understanding the gluten-free diet. Eur. J. Nutr. 2017, 56, 449-459. [CrossRef]

40. Wild, D.; Robins, G.G.; Burley, V.J.; Howdle, P.D. Evidence of high sugar intake, and low fibre and mineral intake, in the gluten-free diet. Aliment. Pharmacol. Ther. 2010, 32, 573-581. [CrossRef]

41. Mariani, P.; Viti, M.G.; Montuori, M.; La Vecchia, A.; Cipolletta, E.; Calvani, L.; Bonamico, M. The gluten-free diet: A nutritional risk factor for adolescents with celiac disease? J. Pediatr. Gastroenterol. Nutr. 1998, 27, 519-523. [CrossRef] [PubMed]

42. Thompson, T.; Dennis, M.; Higgins, L.A.; Lees, A.R.; Sharrett, M.K. Gluten-free diet survey: Are Americans with celiac disease consuming recommended amounts of fibre, iron, calcium and grain foods? J. Hum. Nutr. Diet. 2005, 18, 163-169. [CrossRef] [PubMed]

43. Miranda, J.; Lasa, A.; Bustamante, M.A.; Churruca, I.; Simon, E. Nutritional differences between a gluten-free diet and a diet containing equivalent products with gluten. Plant Foods Hum. Nutr. 2014, 69, 182-187. [CrossRef] [PubMed]

44. Foster-Powell, K.; Holt, S.H.; Brand-Miller, J.C. International table of glycemic index and glycemic load values: 2002. Am. J. Clin. Nutr. 2002, 76, 5-56. [CrossRef]

45. Ferrara, P.; Cicala, M.; Tiberi, E.; Spadaccio, C.; Marcella, L.; Gatto, A.; Calzolari, P.; Castellucci, G. High fat consumption in children with celiac disease. Acta Gastroenterol. Belg. 2009, 72, 296-300.

46. Farnetti, S.; Zocco, M.A.; Garcovich, M.; Gasbarrini, A.; Capristo, E. Functional and metabolic disorders in celiac disease: New implications for nutritional treatment. J. Med. Food 2014, 17, 1159-1164. [CrossRef]

47. Cardoso-Silva, D.; Delbue, D.; Itzlinger, A.; Moerkens, R.; Withoff, S.; Branchi, F.; Schumann, M. Intestinal Barrier Function in Gluten-Related Disorders. Nutrients 2019, 11, 2325. [CrossRef]

48. Marasco, G.; Di Biase, A.R.; Schiumerini, R.; Eusebi, L.H.; Iughetti, L.; Ravaioli, F.; Scaioli, E.; Colecchia, A.; Festi, D. Gut Microbiota and Celiac Disease. Dig. Dis. Sci. 2016, 61, 1461-1472. [CrossRef]

49. Gabrieli, D.; Ciccone, F.; Capannolo, A.; Viscido, A.; Valerii, G.; Serva, D.; Necozione, S.; Coletti, G.; Calvisi, G.; Melideo, D.; et al. Subtypes of chronic gastritis in patients with celiac disease before and after gluten-free diet. United Eur. Gastroenterol. J. 2017, 5, 805-810. [CrossRef]

50. Miele, L.; Valenza, V.; La Torre, G.; Montalto, M.; Cammarota, G.; Ricci, R.; Mascianà, R.; Forgione, A.; Gabrieli, M.L.; Perotti, G.; et al. Increased intestinal permeability and tight junction alterations in nonalcoholic fatty liver disease. Hepatology 2009, 49, 1877-1887. [CrossRef]

51. Rostami-Nejad, M.; Haldane, T.; Aldulaimi, D.; Alavian, S.M.; Zali, M.R.; Rostami, K. The role of celiac disease in severity of liver disorders and effect of a gluten free diet on diseases improvement. Hepat. Mon. 2013, 13, 11893. [CrossRef] [PubMed]

52. Melini, V.; Melini, F. Gluten-Free Diet: Gaps and Needs for a Healthier Diet. Nutrients 2019, 11, 170. [CrossRef] [PubMed]

53. Lerner, A.; O’Bryan, T.; Matthias, T. Navigating the Gluten-Free Boom: The Dark Side of Gluten Free Diet. Front. Pediatr. 2019, 7, 414. [CrossRef] [PubMed]

54. Taetzsch, A.; Das, S.K.; Brown, C.; Krauss, A.; Silver, R.E.; Roberts, S.B. Are Gluten-Free Diets More Nutritious? An Evaluation of Self-Selected and Recommended Gluten-Free and Gluten-Containing Dietary Patterns. Nutrients 2018, 10, 1881. [CrossRef]

55. Hanci, O.; Jeanes, Y.M. Are gluten-free food staples accessible to all patients with coeliac disease? Frontline Gastroenterol. 2019, 10, 222-228. [CrossRef]

56. Passananti, V.; Santonicola, A.; Bucci, C.; Andreozzi, P.; Ranaudo, A.; Di Giacomo, D.V.; Ciacci, C. Bone mass in women with celiac disease: Role of exercise and gluten-free diet. Dig. Liver Dis. 2012, 44, 379-383. [CrossRef]

57. Siniscalchi, M.; Iovino, P.; Tortora, R.; Forestiero, S.; Somma, A.; Capuano, L.; Franzese, M.D.; Sabbatini, F.; Ciacci, C. Fatigue in adult coeliac disease. Aliment. Pharmacol. Ther. 2005, 22, 489-494. [CrossRef]

58. American Diabetes Association. Classification and Diagnosis of Diabetes: Standards of Medical Care in Diabetes-2020. Diabetes Care 2020, 43 (Suppl. S1), S14-S31. [CrossRef]

59. Potter, M.D.E.; Brienesse, S.C.; Walker, M.M.; Boyle, A.; Talley, N.J. Effect of the gluten-free diet on cardiovascular risk factors in patients with coeliac disease: A systematic review. J. Gastroenterol. Hepatol. 2018, 33, 781-791. [CrossRef] 
60. Emilsson, L.; Lebwohl, B.; Sundström, J.; Ludvigsson, J.F. Cardiovascular disease in patients with coeliac disease: A systematic review and meta-analysis. Dig. Liver Dis. 2015, 47, 847-852. [CrossRef]

61. Holmes, G.K.T.; Muirhead, A. Mortality in coeliac disease: A population-based cohort study from a single centre in Southern Derbyshire, UK. BMJ Open Gastroenterol. 2018, 5, 000201. [CrossRef] [PubMed]

(C) 2020 by the authors. Licensee MDPI, Basel, Switzerland. This article is an open access article distributed under the terms and conditions of the Creative Commons Attribution (CC BY) license (http://creativecommons.org/licenses/by/4.0/). 